\title{
Emulsion Mapping in Pork Meat Emulsion Systems with Various Lipid Types and Brown Rice Fiber
}

\author{
Yun-Sang Choi ${ }^{1}$, Young-Boong Kim¹, Hyun-Wook Kim, Ko-Eun Hwang, Dong-Heon Song, \\ Tae-Jun Jeong, Jinhee Park ${ }^{2}$, and Cheon-Jei Kim* \\ Department of Food Science and Biotechnology of Animal Resources, Konkuk University, Seoul 143-701, Korea \\ ${ }^{I}$ Food Processing Research Center, Korean Food Research Institute, Seongnam 463-746, Korea \\ ${ }^{2}$ Food Ingredients Solution Center, CJ Cheiljedang Corporation, Seoul 152-051, Korea
}

\begin{abstract}
This study was conducted to evaluate emulsion mapping between emulsion stability and cooking yields, apparent viscosity, and hardness of reduced-fat pork emulsion systems. The reduced-fat emulsion systems were supplemented with different lipid types and brown rice bran fiber (BRF) concentrations. Compared to the control with 30\% back fat, lower emulsion stability and higher cooking yield of meat emulsion systems were observed in T1 (30\% back fat $+1 \%$ BRF), T2 (30\% back fat $+2 \%$ BRF), T3 (30\% back fat $+3 \%$ BRF), T4 (30\% back fat $+6 \%$ $\mathrm{BRF})$, and $\mathrm{T} 15(10 \%$ back fat $+10 \%$ canola oil $+2 \% \mathrm{BRF})$. Lower emulsion stability and higher apparent viscosity were observed in $\mathrm{T} 1$, $\mathrm{T} 2$, T3, T4, and T8 (20\% back fat $+3 \%$ BRF) compared to the control. Lower emulsion stability and higher hardness was detected in all treatments compared with the control, except T5 (20\% back fat), T10 (10\% back fat $+10 \%$ canola oil $+2 \%$ BRF), T11 ( $10 \%$ back fat $+10 \%$ olive oil $+2 \%$ BRF), T12 (10\% back fat $+10 \%$ grape seed oil $+2 \%$ BRF), and T13 (10\% back fat $+10 \%$ soybean oil $+2 \%$ BRF). This approach has been found particularly useful for highlighting differences among the emulsified properties in emulsion meat products. Thus, the results obtained with emulsion mapping are useful in making emulsified meat products of desired quality characteristics, partially replacing pork back fat with a mix of $10 \%$ back fat, $10 \%$ canola oil and $2 \%$ BRF was most similar to the control with $30 \%$ pork back fat.
\end{abstract}

Key words: emulsion mapping, reduced-fat, dietary fiber, brown rice fiber, emulsion stability

Received August 18, 2014 / Revised October 6, 2014 / Accepted October 9, 2014

\section{Introduction}

Emulsion meat products are very popular worldwide, and traditional emulsion meat products contain up to $30 \%$ fat (Choi et al., 2010). Fat plays major roles in processing of emulsion meat products, stabilizing the meat emulsion, reducing cooking loss, and improving viscosity and textural properties (Choi et al., 2009). It is also an important source of energy, essential fatty acids, and fat soluble vitamins (Choi et al., 2013). However, a diet with high animal fat is also associated with obesity, hypertension, cardiovascular disease, and coronary heart diseases, because of high amounts of saturated fatty acids and cholesterol (Marchetti et al., 2014). In emulsion meat products, higher levels of animal fat have been reduced, as consumers have demanded reduced-fat or low-fat meat

\footnotetext{
*Corresponding author: Cheon-Jei Kim, Department of Food Science and Biotechnology of Animal Resources, Konkuk University, Seoul 143-701, Korea. Tel: +82-2-450-3684; Fax: +822-444-6695, E-mail: kimcj@konkuk.ac.kr
}

products (Fernández-Ginés et al., 2004; Fernández-López et al., 2008; Hughes et al., 1998; Yilmaz, 2005). The need for reduced-fat/low-fat diets has caused the meat product industry to develop or modify meat products to contain less animal fat (Luruena-Martinez et al., 2004).

Vegetable oil is free of cholesterol and has a higher ratio of unsaturated to saturated fatty acids than animal fat (Choi et al., 2010). However, vegetable oils alone do not seem technologically suitable for simple replacement use, due to their differing physical properties. Thus, the incorporation of vegetable oils with dietary fiber in meat products to replace animal fat has been attempted and may have positive effects on consumer health (Choi et al., 2013).

Dietary fiber may also be added to meat emulsion products to enhance textural properties and emulsion stability, because dietary fiber has water retention capacity and water and fat binding properties. Furthermore, dietary fiber is desirable not only functionally and technologically, but also for its nutritional value (Ktari et al., 2014). Some researchers have evaluated various natural sources of dietary fiber (Choi et al., 2009; Cofrades et al., 2000; Fernán- 
dez-Ginés et al., 2004; Fernández-López et al., 2008; Huang et al., 2005; Vural et al., 2004), but few studies have reported on dietary fiber extracted from brown rice added in various formulation to emulsion meat products. Reduced-fat meat emulsions containing brown rice fiber (BRF) may be optimal in terms of emulsion properties.

Emulsion mapping is an important and useful methodology for modeling and analyzing meat product characteristics. Mapping techniques have been used for many different purposes such as identifying sensory drivers of linking, finding the best product composition, and as a method of product optimization. The vital advantage of mapping techniques is that they are simple to use and interpret and thus provide non-statisticians with useful information (Endrizzi et al., 2014). Furthermore, the mapping results can be used to propose a new useful approach based on permutation testing (Morrison et al., 2011). This mapping information can be important in research and development activities after (Hopfer and Heymann, 2013). An improved understanding of the determinants of meat products in general is important developing in interventions aimed at specifically altering product properties. Therefore, it is vital to understand the interrelationships between emulsion stability and cooking yields, apparent viscosity, and hardness because of their relationship to the ultimate quality of emulsion meat products.

The objective of this study was to evaluate emulsion mapping systems in replacing animal fat with various levels of vegetable oils and dietary fiber extracted from brown rice by studying the relationship among emulsion stability, cooking yield, apparent viscosity, and the hardness of reduced-fat meat emulsions.

\section{Materials and Methods}

\section{Preparation of dietary fiber from brown rice bran (BRF)}

BRF was prepared from brown rice bran using the method of Park et al. (2009). Fresh rice bran, containing 12$16 \%$ moisture, was obtained from a polishing plant in China. The rice bran was pelletized into a $2-10 \mathrm{~mm}$ size using a pellet-forming machine. The rice bran pellets were dried until the moisture content was $<10 \%$. Hexane (2-5 fold by weight) was added and circulative lipid-extraction was conducted until the residual oil content in the rice bran was $3 \%$. De-fatted rice bran was obtained by removing the residual hexane at a temperature $<60^{\circ} \mathrm{C}$. To the de-fatted rice bran, 8-40 fold of water by weight was added, and the mixture was stirred with shaking for 30-60 min to uniformly disperse the particles in the mixture. Subsequently, $3 \mathrm{~N} \mathrm{NaOH}$ was slowly added to the mixture at $20-30^{\circ} \mathrm{C}$ to adjust the $\mathrm{pH}$ to $8-10$, and protein was extracted for 30-60 $\mathrm{min}$. The resulting protein solution was centrifuged at more than $5,000 \mathrm{~g}$ and ambient temperature. The precipitate was dried, crushed, sieved, roasted, cooled, pulverized, and sieved to prepare the BRF. The roasting and pulverization processes were performed to increase the microbiological safety and sensory preference during the food application.

\section{Preparation of a pork emulsion system}

Fresh pork (M. biceps femoris, M. semitendinosus, $M$. semimembranosus, moisture, $71.97 \%$; fat, $4.96 \%$; protein, $15.82 \%$ ) and pork back fat (moisture, $12.61 \%$; fat, $85.64 \%$ ) were purchased from a local processor at $48 \mathrm{~h}$ postmortem. All subcutaneous and intramuscular fat and visible connective tissue were removed from the fresh ham muscle. Lean meat and pork back fat were ground through an $8-\mathrm{mm}$ plate. The ground tissues were vacuum-packaged (FJ-500XL, Fujee Tech, Korea) and stored at $0^{\circ} \mathrm{C}$ until required for product manufacture. Suitable amounts of muscle and fat were tempered at $4^{\circ} \mathrm{C}$ for $24 \mathrm{~h}$ prior to meat batter preparation. Four commercial vegetable oils canola oil, olive oil, grape seed oil, and soybean oil - were assessed to replace pork fat obtained from a local market. All vegetable oils were pre-emulsified on the day of use, according to the method of Choi et al. (2010). The first meat emulsion batter was the control, prepared with $30 \%$ pork back fat. The others meat emulsion systems were produced to the experimental design; the compositions are given in Table 1. Each batch of samples consisted of emulsion systems differing in composition with respect to the pork back fat, vegetable oil, and BRF level added. Pork meat was homogenized and emulsified for $1 \mathrm{~min}$ in a silent cutter (Cutter Nr-963009, Hermann Scharfen GmbH \& Co, Germany). Nitrite pickled salt (NPS) $(1.5 \%)$, sodium tripolyphosphate $(0.5 \%)$, ascorbic acid $(0.02 \%)$, monosodium L-glutamate $(0.06 \%)$, and bratwurst spice $(0.6 \%)$ were added to the meat emulsion batters, which had been previously dissolved in water and chilled $\left(2^{\circ} \mathrm{C}\right)$ and then mixed for $1 \mathrm{~min}$. BRF was added to the samples and the batters were emulsified for $6 \mathrm{~min}$. A temperature probe (Kane-May, KM330, UK) was used to monitor the emulsion temperature, which was maintained at $<10^{\circ} \mathrm{C}$ throughout batter preparation. After emulsification, the meat batter was stuffed into collagen casings (\#240, NIPPI Inc., Japan; approximate diameter of $25 \mathrm{~mm}$ ) using a stuffer (Stuffer IS-8, Sirman, Italy). The meat batter samples were 
Table 1. Meat emulsion systems formulation with varying vegetable oil (canola oil ${ }^{1)}$, olive oil ${ }^{2}$, grape seed oil $^{3)}$, and soybean oil ${ }^{4)}$ ) and brown rice fiber levels $(1,2,3,4$, and $6 \%)$

\begin{tabular}{|c|c|c|c|c|c|c|c|c|c|c|c|c|c|c|c|c|c|c|}
\hline \multirow{2}{*}{ Ingredients } & \multicolumn{18}{|c|}{ Treatments (\%) } \\
\hline & Control & T1 & $\mathrm{T} 2$ & T3 & $\mathrm{T} 4$ & $\mathrm{~T} 5$ & T6 & $\mathrm{T} 7$ & $\mathrm{~T} 8$ & T9 & T10 & T11 & T12 & T13 & T14 & T15 & T16 & $\mathrm{T} 17$ \\
\hline Pork meat & 50 & 50 & 50 & 50 & 50 & 50 & 50 & 50 & 50 & 50 & 50 & 50 & 50 & 50 & 50 & 50 & 50 & 50 \\
\hline Pork back fat & 30 & 30 & 30 & 30 & 30 & 20 & 20 & 20 & 20 & 20 & 10 & 10 & 10 & 10 & 10 & 10 & 10 & 10 \\
\hline Vegetable oil & - & - & - & - & - & - & - & - & - & - & $10^{\mathrm{a})}$ & $10^{b)}$ & $10^{c)}$ & $10^{d)}$ & $10^{\text {a) }}$ & $10^{\text {a) }}$ & $10^{\text {a) }}$ & $10^{\text {a) }}$ \\
\hline Ice water & 20 & 19 & 18 & 17 & 14 & 30 & 29 & 28 & 27 & 24 & 28 & 28 & 28 & 28 & 29 & 28 & 26 & 26 \\
\hline Brown rice fiber & - & 1 & 2 & 3 & 6 & - & 1 & 2 & 3 & 6 & 2 & 2 & 2 & 2 & 1 & 2 & 3 & 4 \\
\hline Total & 100 & 100 & 100 & 100 & 100 & 100 & 100 & 100 & 100 & 100 & 100 & 100 & 100 & 100 & 100 & 100 & 100 & 100 \\
\hline
\end{tabular}

${ }^{1)}$ canola oil, ${ }^{2)}$ olive oil, ${ }^{3)}$ grape seed oil, ${ }^{4)}$ soybean oil.

then heated to $75 \pm 2^{\circ} \mathrm{C}$ for $30 \mathrm{~min}$ in a water bath (Model 10-101, Dae Han Co, Korea). The cooked meat batter was cooled with cold water $\left(15^{\circ} \mathrm{C}\right)$. The emulsion system was then placed in polyethylene bags, vacuum-packaged using a vacuum packaging system, and maintained at $<$ $10^{\circ} \mathrm{C}$ during preparation. This procedure was performed in triplicate for each emulsion systems (each using $10 \mathrm{~kg}$ frankfurters). All analyses were conducted in triplicate for each formulation.

\section{Proximate composition}

Compositional properties of the raw meat batters were determined using AOAC (2000). Moisture content was determined by weight loss after $12 \mathrm{~h}$ of drying at $105^{\circ} \mathrm{C}$ in a drying oven (SW-90D, Sang Woo Scienctific Co., Korea). Fat content was determined by Soxhlet method with a solvent extraction system (Soxtec ${ }^{\circledR}$ Avanti 2050 Auto System, Foss Tecator AB, Sweden) and protein was determined by Kjeldahl method with an automatic Kjeldahl nitrogen analyzer (Kjeltec ${ }^{\circledR} 2300$ Analyzer Unit, Foss Tecator AB, Sweden). Ash was determined according to AOAC method 923.03.

\section{Dietary fiber measurements}

Duplicate fat free dry was analyzed for total dietary fiber using the method of Lee et al. (1992). The method includes enzymatic hydrolysis with -amylase, protease, and amyloglucosidase, using the Mes-Tris buffer. Triplicate of approximately $1 \mathrm{~g}$ samples were suspended in 40 $\mathrm{mL}$ Mes-Tris buffer, and submitted to an enzymatic hydrolysis sequence: $50 \mathrm{~mL}$ of thermo-resistant -amylase, a water bath for $35 \mathrm{~min}$, and $100 \mathrm{iL}$ of protease in water bath at $60^{\circ} \mathrm{C}$ for $30 \mathrm{~min}$. After that, the $\mathrm{pH}$ was corrected to the range of 4.0-4.7, and in water bath at $60^{\circ} \mathrm{C}$ for 30 min, $300 \mu \mathrm{L}$ amyloglucosidase was added. Finally, the fiber was precipitated with $95 \%$ ethanol at $60^{\circ} \mathrm{C}$. The sample was filtered in fritted glass crucibles, with glass wool as a filtration agent. The crucibles containing the residue were dried in a $105^{\circ} \mathrm{C}$ dry oven, cooled in a dessicator, and weighed.

\section{Emulsion stability}

The emulsion systems were analyzed for emulsion stability using the method of Bloukas and Honikel (1992) with the following modifications. At the middle of a 15 mesh sieve, pre-weighed graduated glass tubes (Pyrex Chojalab Co., Korea, volume: $15 \mathrm{~mL}$, graduated units: 0.2 $\mathrm{mL}$ ) were filled with emulsion batter. The glass tubes were closed and heated for $30 \mathrm{~min}$ in a boiling water bath to a core temperature of $75 \pm 1^{\circ} \mathrm{C}$. After cooling to $4 \pm 1^{\circ} \mathrm{C}$, water and fat separated in each graduated glass tube were measured and emulsion stability was calculated as given below (Choi et al., 2007).

Emulsion stability $(\%)=[($ volume of water layer $(\mathrm{mL})$ + volume of fat layer $(\mathrm{mL}))$ / weight of raw meat batter (g) $] \times 100$

\section{Cooking yield}

The meat batters were weighed before heat processing and after cooling at $15^{\circ} \mathrm{C}$ for $2 \mathrm{~h}$. The cooking yield was determined from their weights and expressed as a percentage of the initial weight.

Cooking yield $(\%)=$ [meat batters weight after cooking (g) / meat batters weight before cooking $(\mathrm{g})] \times 100$

\section{Apparent viscosity}

Emulsion system viscosity was measured in triplicate with a rotational viscometer (HAKKE Viscotester 500, Thermo Electron Corp., Germany) set at $10 \mathrm{rpm}$. The standard cylnder sensor (SV-2) was positioned in a $25 \mathrm{~mL}$ metal cup filled with batter and allowed to rotate under a constant share rate at $\mathrm{s}^{-1}$ for $60 \mathrm{~s}$ before each reading was taken. Apparent viscosity values in centipoises were obtained (Shand, 2000). 


\section{Hardness}

Hardness was performed at room temperature with a texture analyzer (TA-XT2 $i$, Stable Micro Systems, UK). Emulsion system samples were taken from the central portion of each meat batter preparation. Prior to analysis, samples were equilibrated to the room temperature $\left(20^{\circ} \mathrm{C}\right.$, $3 \mathrm{~h}$ ). The hardness analysis conditions were as follows: pre-test speed, $2.0 \mathrm{~mm} / \mathrm{s}$; post-test speed, $5.0 \mathrm{~mm} / \mathrm{s}$; maximum load, $2 \mathrm{~kg}$; head speed, $2.0 \mathrm{~mm} / \mathrm{s}$; distance, $8.0 \mathrm{~mm}$; force, $5 \mathrm{~g}$. Values for hardness $(\mathrm{kg})$ were determined as described previously (Bourne, 1978).

\section{Statistical analysis}

Average values of the emulsion stability, cooking yields, apparent viscosity and hardness were compared by the correlations between pairs of variables were calculated as Pearson's correlation coefficients. The statistical analyses were done in the Analyst application within the SAS system statistical software 9.2 (SAS Institute, USA).

\section{Results and Discussion}

\section{Proximate composition of BRF}

The moisture contents of BRF was $4.23 \%$, the protein contents was $10.22 \%$, the fat contents was $1.25 \%$, the ash contents was $15.09 \%$, the dietary fiber $55.12 \%$.

\section{Emulsion mappings between emulsion stability and cooking yield}

The emulsion mapping between emulsion stability and cooking yields of meat emulsion systems with various lipid types (animal fat and/or vegetable oil) and BRF levels is presented in Fig. 1. The formulations indicating low emulsion stability and high cooking yields were T1, T2, T3, T4, and T15 treatments, versus the control with 30\% back fat. Cooking yields in the emulsion systems showed a decreasing trend with reduced fat levels, and the meat emulsion systems with increasing BRF levels showed increased cooking yield. T5 had the lowest cooking yield, while T4 had the highest cooking yield. Lower cooking yield and higher emulsion stability were observed in T5, $\mathrm{T} 11, \mathrm{~T} 12$, and T13 than in the control with $30 \%$ back fat. Some researchers have reported that dietary fiber can be added to emulsion meat products to increase cooking yield due to its water and fat binding properties (Choi et al., 2010; Fernández-Ginés et al., 2004; Piñero et al., 2008). Generally, the emulsion systems with decreased added fat concentrations had lower cooking yields and

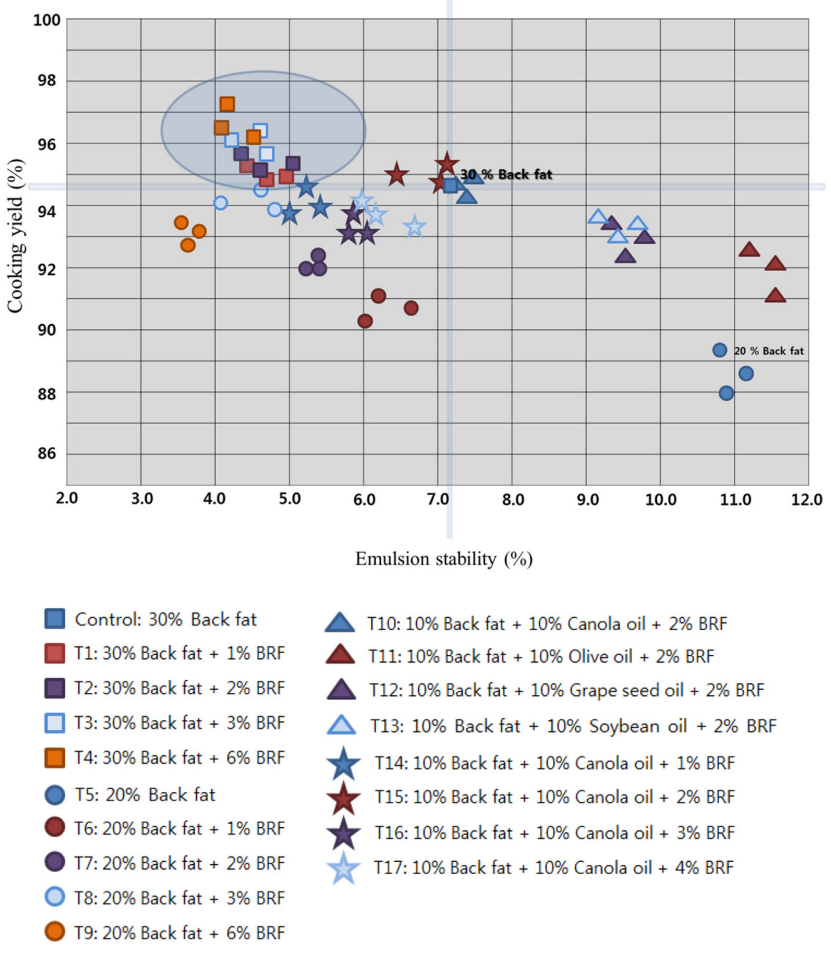

Fig. 1. Emulsion mapping between emulsion stability and cooking yield for meat emulsion systems containing various lipid types and brown rice fiber (BRF) levels.

higher emulsion stability. Furthermore, dietary fiber improved the physical properties of the emulsion meat products by influencing the matrix structure, because meat products provide the greatest emulsion stability (Choi et al., 2011). Similar results were obtained by Choi et al. (2009) in which meat products with added dietary fiber showed increased cooking yields and decreased emulsion stability, due to enhanced emulsion gel matrix structures through improved water and fat binding capacities. This effect was also observed by Cofrades et al. (2008): higher cooking yields and lower emulsion stability of meat batter with added dietary fiber. Wong and Cheung (2000) reported that the major contribution to water binding in their meat products was added dietary fiber from seaweeds, which resulted in improved cooking yields and emulsion stability. These results also agree with those reported by Choi et al. (2013), who observed a decrease in emulsion stability in a reduced-fat frankfurter with reduced pork back fat levels, by partially substituting pork fat with a mix of vegetable oil and dietary fiber. Thus, the ability to control cooking yields and emulsion stability is affected by the lipid type, fat and moisture concentration, and ingredients such as dietary fiber. 


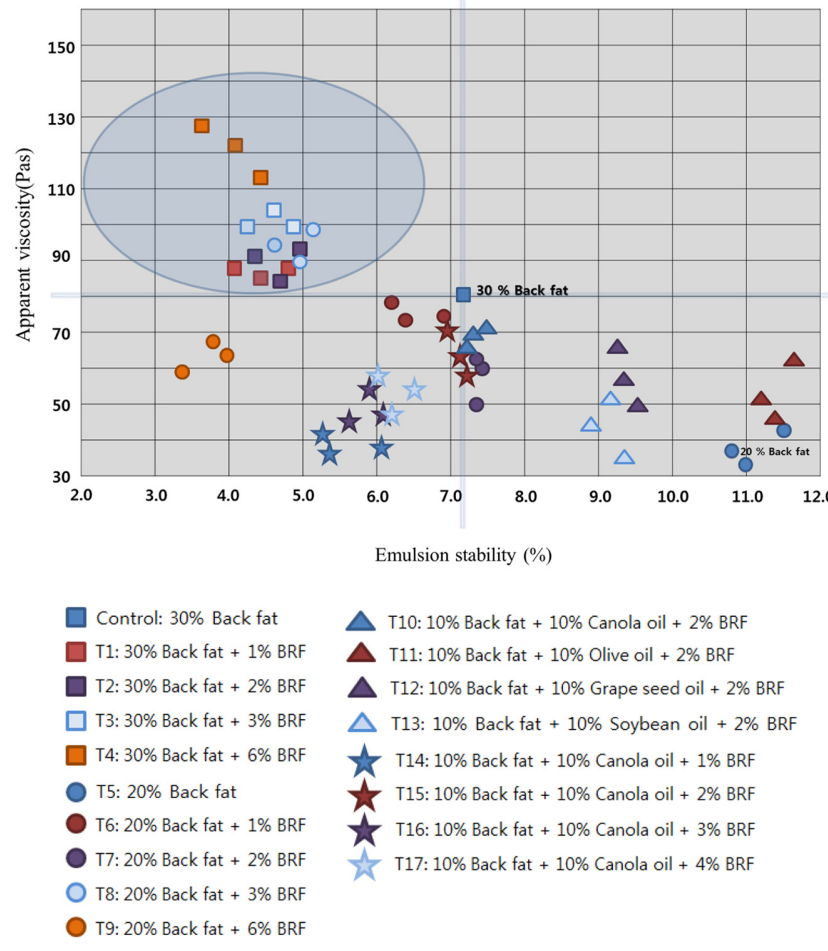

Fig. 2. Emulsion mapping between emulsion stability and apparent viscosity for meat emulsion systems containing various lipid types and brown rice fiber (BRF) levels.

\section{Emulsion mappings between emulsion stability and apparent viscosity}

Fig. 2 shows the emulsion mapping between emulsion stability and apparent viscosity of the meat emulsion systems with various lipid types (animal fat and/or vegetable oil) and BRF levels. Apparent viscosity was affected by the type of fat, fat and moisture concentration, and dietary fiber levels. Higher apparent viscosity and lower emulsion stability were seen in $\mathrm{T} 1, \mathrm{~T} 2, \mathrm{~T} 3, \mathrm{~T} 4$, and $\mathrm{T} 8$ than in the control with $30 \%$ back fat. T5 (20\% back fat) had the lowest apparent viscosity, while increasing the amount of added BRF increased the apparent viscosity. Similar results were reported, that an increase in dietary fiber content while maintaining constant fat and water proportions, showed an increase in viscosity (Claus and Hunt 1991). These results also agree with those reported by Choi et al. (2013), who found that when pork back fat was replaced with vegetable oil and dietary fiber were added to meat emulsion systems, that the addition of dietary fiber increased the binding capacity of the meat emulsions. Lee et al. (2008) reported that increasing the emulsion viscosity of emulsion products resulted in increased emulsion stability. According to Zayas (1997), an indication of the relationship between emulsion viscosity and emulsion
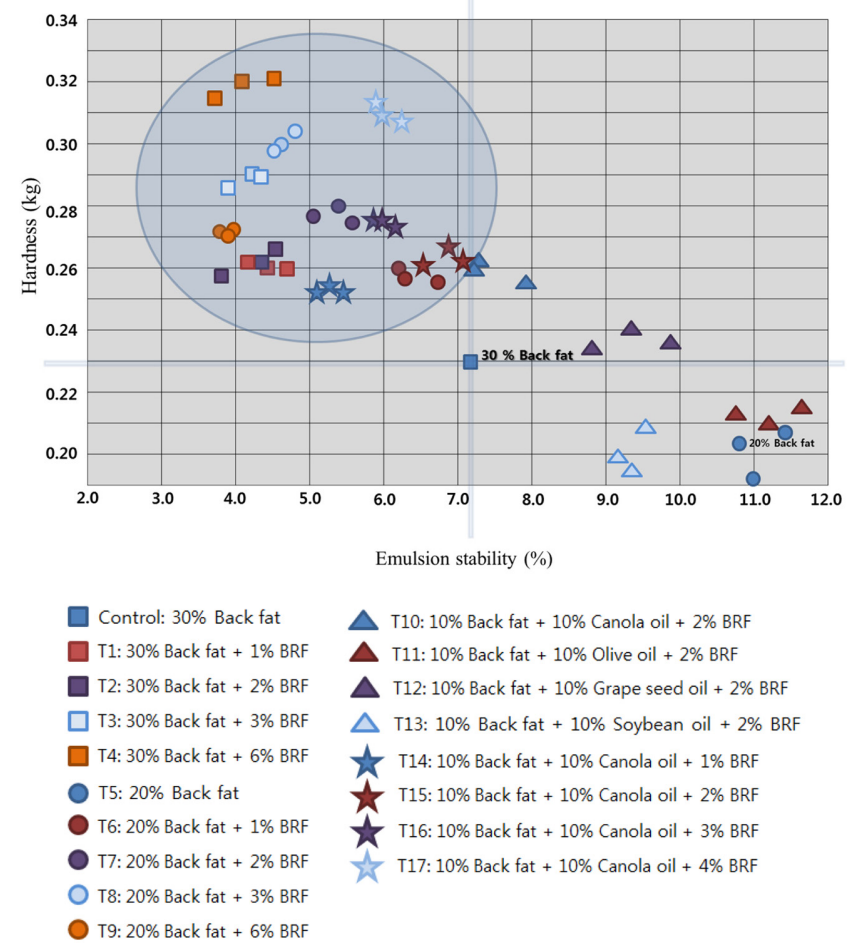

Fig. 3. Emulsion mapping between emulsion stability and hardness for meat emulsion systems containing various lipid types and brown rice fiber (BRF) levels.

stability was a valuable criterion of quality in meat processing. Thus, the relationship between apparent viscosity and emulsion stability of meat emulsion systems can affect quality characteristics of the emulsion meat products, because emulsions with high apparent viscosity also have high emulsion stability.

\section{Emulsion mappings between emulsion stability and hardness}

The emulsion mapping between emulsion stability and hardness of the meat emulsion systems with various lipid types (animal fat and/or vegetable oil) and BRF levels is presented in Fig. 3. Compared with the control, with 30\% back fat, higher emulsion stability and lower hardness were seen with T5, T11, and T13. Treatment with BRF resulted in higher hardness than treatments (control and T5) with only back fat added, except T11 and T13. This result was similar to that of Tobin et al. (2013), which indicated that fat level of emulsion meat products was positively correlated with hardness. These findings also agree with those reported by Choi et al. (2013) who showed the effects of replacing pork back fat with vegetable oil and dietary fiber on textural properties of meat emulsion systems. The results indicated that hardness increa- 
Table 2. Correlation coefficients of emulsion stability, cooking yield, apparent viscosity, and hardness for the 18 different meat emulsion systems types assessed (see Table 1)

\begin{tabular}{ccccc}
\hline \hline Measurements & Emulsion stability & Cooking yield & Apparent viscosity & Hardness \\
\hline Emulsion stability & - & $-0.52^{*}$ & $-0.56^{*}$ & $-0.67^{* *}$ \\
Cooking yield & & - & $0.63^{* *}$ & -0.25 \\
Apparent viscosity & & & - & -0.03
\end{tabular}

*Highly significant statistically at $p<0.05$.

**Highly significant statistically at $p<0.01$.

sed significantly by replacing half the animal fat with vegetable oil and adding dietary fiber. Other studies have indicated that emulsion meat products with added dietary fiber have increased hardness, because of their greater binding ability and water holding capacity (Choi et al., 2009; Eim et al., 2008; Lee et al., 2008; Saricoban et al., 2008). According to Choi et al. (2013), depending on the amount and types of fat, the results have been reported as to their influence on hardness. These results are in agreement with the current study. Accordingly, the present study suggests that the required formulations of finished emulsion meat products may result in the desired hardness and emulsion stability.

Correlation coefficients among the emulsion stability, cooking yields, apparent viscosity, and hardness

Possible relationships among emulsion stability, cooking yields, apparent viscosity, and hardness measured for the different meat emulsion systems with various lipid types and BRF levels were assessed by analysis of Pearson's correlations (Table 2). The Pearson's correlation coefficients show that emulsion stability is negatively correlated with cooking loss $(p<0.05)$, apparent viscosity ( $p<$ $0.05)$, and hardness $(p<0.01)$ with values of $-0.52,-0.56$, and -0.67 , respectively. According to Lee et al. (2008), between emulsion stability and cooking yield of meat emulsion systems had high correlation. Zorba et al. (1993) reported that meat emulsion systems had high correlations between emulsion stability and emulsion viscosity. However, a positive correlation between cooking loss and apparent viscosity $(p<0.01)$ was also observed $(\mathrm{r}=0.63)$. No significant relationship between apparent viscosity and hardness was found for meat emulsion systems. As seen in emulsion mapping in Fig. 1-3, it is confirmed that there is a correlation between emulsion stability and cooking yield, apparent viscosity, and hardness of reduced-fat pork emulsion systems.

\section{Conclusion}

In brief, it can be concluded that the effects of fat con- centration, BRF level, and lipid types showed relationship with emulsion stability and cooking yields, apparent viscosity, and hardness. Emulsion mapping results showed that reduced-fat meat emulsion systems with $20 \%$ back fat and 3\% BRF has the most desirable quality characteristics, except for treatments with $30 \%$ fat concentration (including the control). With the addition of vegetable oil, the treatment, with $10 \%$ back fat, $10 \%$ canola oil, and $2 \%$ BRF was most similar to the control with $30 \%$ pork back fat. These results suggest that emulsion mapping is useful for assessing the quality of emulsified meat products while replacing pork back fat with incorporated vegetable oil and BRF. To improve the quality characteristics of meat emulsion systems with various added lipid types and BRF, more studies are necessary regarding the addition of other ingredients incorporated in meat emulsion systems.

\section{Acknowledgements}

This research was supported High Value added Food Technology Development Program (2014-314068-3) by the Ministry of Agriculture, Food and Rural Affairs (Republic of Korea).

\section{References}

1. AOAC (2000) Official methods of analysis of AOAC, Vol. 41. (17th ed.). Washington DC: Association of Official Analytical Chemists.

2. Bloukas, I. and Honikel, K. O. (1992) The influence of additives on the oxidation of pork back fat and its effect on water and fat binding in finely comminuted batters. Meat Sci. 32, 31-43.

3. Bourne, M. C. (1978) Texture profile analysis. Food Technol. 32, 62-66.

4. Choi, Y. S., Choi, J. H., Han, D. J., Kim, H. Y., Lee, M. A., Kim, H. W., Jeong, J. Y., and Kim, C. J. (2009) Characteristics of low-fat meat emulsion systems with pork fat replaced by vegetable oils and rice bran fiber. Meat Sci. 82, 266-271.

5. Choi, Y. S., Choi, J. H., Han, D. J., Kim, H. Y., Lee, M. A., Kim, H. W., Lee, J. W., Chung, H. J., and Kim, C. J. (2010) Optimization of replacing pork back fat with grape seed oil and rice bran fiber for reduced-fat meat emulsion systems. Meat Sci. 84, 212-218. 
6. Choi, Y. S., Choi, J. H., Han, D. J., Kim, H. Y., Lee, M. A., Kim, H. W., Jeong, J. Y., and Kim, C. J. (2011) Effects of rice bran fiber on heat-induced gel prepared with pork salt-soluble meat proteins in model system. Meat Sci. 88, 59-66.

7. Choi, Y. S., Lee, M. A., Jeong, J. Y., Choi, J. H., Han, D. J., Kim, H. Y., Lee, E. S., and Kim, C. J. (2007) Effects of wheat fiber on the quality of meat batter. Korean J. Food Sci. An. 27, 22-28.

8. Choi, Y. S., Park, K. S., Kim, H. W., Hwang, K. E., Song, D. H., Choi, M. S., Lee, S. Y., Paik, H. D., and Kim, C. J. (2013) Quality characteristics of reduced-fat frankfurters with pork fat replaced by sunflower seed oils and dietary fiber extracted from makgeolli lees. Meat Sci. 93, 652-658.

9. Claus, J. R. and Hunt, M. C. (1991) Low-fat, high-added water bologna formulated with texture-modifying ingredients. $J$. Food Sci. 56, 643-647.

10. Cofrades, S., Guerra, M. A., Carballo, J., Fernandes-Martin, F., and Colmenero, F. J. (2000) Plasma protein and soy fiber content effect on bologna sausage properties as influenced by fat level. J. Food Sci. 65, 281-287.

11. Cofrades, S., Lopez-Lopez, I., Solas, M. T., Bravo, L., and Jimenez-Colmenero, F. (2008) Influence of different types and proportions of added edible seaweeds on characteristics of lowsalt gel/emulsion meat systems. Meat Sci. 79, 767-776.

12. Eim, V. S., Simal, S., Rosselló, C., and Femenia, A. (2008) Effects of addition of carrot dietary fibre on the ripening process of a dry fermented sausage (sobrassada). Meat Sci. 80, 173-182.

13. Endrizzi, I., Gasperi, F., Rodbotten, M., and Naes, T. (2014) Interpretation, validation and segmentation of preference mapping models. Food Qual. Prefer. 32, 198-209.

14. Fernández-Ginés, J. M., Fernandez-López, J., Sayas-Barberá, E., Sendra, E., and Pérez-Álvarez, J. A. (2004) Lemon albedo as a new source of dietary fiber: Application to bologna sausages. Meat Sci. 67, 7-13.

15. Fernández-López, J., Sendra, E., Sayas-Barberá, E., Navarro, C., and Pérez-Alvarez, J. A. (2008) Physico-chemical and microbiological profiles of "salchichón" (Spanish dry-fermented sausage) enriched with orange fiber. Meat Sci. 80, 410-417.

16. Hopfer, H. and Heymann, H. (2013) A summary of projective mapping observations - the effect of replicates and shape, and individual performance measurements. Food Qual. Prefer. 28, 164-181.

17. Huang, S. C., Shiau, C. Y., Liu, T. E., Chu, C. L., and Hwang, D. F. (2005) Effects of rice bran on sensory and physico-chemical properties of emulsified pork meatballs. Meat Sci. 70, 613-619.

18. Hughes, E., Mullen, A. M., and Troy, D. J. (1998) Effects of fat level, tapioca starch and whey protein in frankfurters formulated with 5\% and 12\% fat. Meat Sci. 48, 169-180.

19. Ktari, N., Smaoui, S., Trabelsi, I., Nasri, M., and Salah, R. B. (2014) Chemical composition, techno-functional and sensory properties and effects of three dietary fibers on the quality characteristics of Tunisian beef sausage. Meat Sci. 96, 521-525.

20. Lee, M. A., Han, D. J., Jeong, J. Y., Choi, J. H., Choi, Y. S., Kim, H. Y., Paik, H. D., and Kim, C. J. (2008) Effect of kim- chi powder level and drying methods on quality characteristics of breakfast sausage. Meat Sci. 80, 708-714.

21. Lee, S. C., Prosky, L., and Devries, J. W. (1992) Determination of total, soluble, and insoluble dietary fiber in foods. Enzymatic-gravimetric method, MES-TRIS buffer: collaborative study. J. Assoc. Off. Anal Chem. 75, 395-416.

22. Luruena-Martinez, M. A., Vivar-Quintana, A. M., and Revilla, I. (2004) Effect of locust bean/xanthan gum addition and replacement of pork fat with olive oil on the quality characteristics of low-fat frankfurters. Meat Sci. 68, 383-389.

23. Marchetti, L., Andres, S. C., and Califano, A. N. (2014) Lowfat meat sausages with fish oil: Optimization of milk proteins and carrageenan contents using response surface methodology. Meat Sci. 96, 1297-1301.

24. Morrison, K. T., Nelson, T. A., and Ostry, A. S. (2011) Methods for mapping local food production capacity from agricultural statistics. Agr. Syst. 104, 491-499.

25. Park, H. J., Han, S. W., Lee, D. Y., Kim, H. K., Jeong, H. C., Park, H. H., and Song, S. H. (2009) A method for preparing protein concentrate from rice bran. International Publication Number WO 2009/035186 A1.

26. Piñero, M. P., Parra, K., Huerta-Leidenz, N., Arenas de Moreno, L., Ferrer, M., Araujo, S., and Barboza, Y. (2008) Effect of oat's soluble fibre ( $\beta$-glucan) as a fat replacer on physical, chemical, microbiological and sensory properties of low-fat beef patties. Meat Sci. 80, 675-680.

27. Saricoban, C., Ozalp, B., Yilmaz, M. T., Ozen, G., Karakaya, M., and Akbulut, M. (2008) Characteristics of meat emulsion systems as influenced by different levels of lemon albedo. Meat Sci. 80, 599-606.

28. SAS (2008) SAS/STAT Software. Release 9.2, SAS Institute Inc., Cary, NC, USA.

29. Shand, P. J. (2000) Textural, water holding, and sensory properties of low-fat pork bologna with normail and waxy starch hull-less barley. J. Food Sci. 65, 101-107.

30. Tobin, B. D., O’Sullivan, M. G., Hamill, R. M., and Kerry, J. P. (2013) The impact of salt and fat level variation on the physiochemical properties and sensory quality of pork breakfast sausages. Meat Sci. 93, 145-152.

31. Wong, K. H. and Cheung, P. C. K. (2000) Nutritional evaluation of some subtropical red and green seaweeds Part 1 - proximate composition, amino acid profiles and some physicchemical properties. Food Chem. 71, 475-782.

32. Vural, H., Javidipour, I., and Ozbas, O. O. (2004) Effects of interesterified vegetable oils and sugarbeet fiber on the quality of frankfurters. Meat Sci. 67, 65-72.

33. Yilmaz, I. (2005) Physicochemical and sensory characteristics of low fat meatballs with added wheat bran. J. Food Eng. 69, 369-373.

34. Zayas, J. F. (1997) Emulsifying properties of proteins. In: J. F., Zayas (Ed.). Functionality of proteins in food. Berlin, Germany: Springer-Verlag Berlin Heigedlbeg, pp. 134-227.

35. Zorba, O., Gokalp, H. Y., Yetim, H., and Ockerman, H. W. (1993) Salt, phosphate and oil temperature effects on emulsion capacity of fresh or frozen meat and sheep tail fat. $J$. Food Sci. 58, 492-496. 